\section{ALIANÇA ESTRATÉGICA ENTRE INSTITUIÇÕES DE ENSINO SUPERIOR: GERANDO MESTRADOS E DOUTORADOS INTERINSTITUCIONAIS}

\section{RESUMO}

As Instituições de Ensino Superior (IES) precisam estar atentas às rápidas mudanças econômicas, políticas, sociais e culturais ocorridas no mundo globalizado e também flexíveis para a possibilidade de inovarem seus processos e serviços, favorecendo as chances de vantagem competitiva. Para acompanhar estas mudanças, as empresas procuram investir em treinamentos e capacitações. Apesar da acentuada expansão de cursos de graduação e de pós graduação ocorrida no Brasil, nota-se que este avanço ainda não é suficiente e nem atende às necessidades da maioria das regiões brasileiras. Nesse cenário, surgem os Mestrados e Doutorados Interinstitucionais, que buscam capacitar profissionais e criarem ou expandirem centros de pesquisas em regiões geográficas menos favorecidas. Sendo assim, busca-se verificar como ocorrem as alianças entre IES; conhecer os principais benefícios advindos destas alianças para as instituições envolvidas; identificar os mestrados e doutorados interinstitucionais que estão ocorrendo no Brasil na área de Administração. Para tanto, realizou-se uma pesquisa, de caráter exploratório. Os resultados apontam que o estabelecimento de parcerias interinstitucionais é útil para as IES, na medida em que favorece compartilhamento e criação de conhecimentos, agregando, assim, valor de inovação no mercado educacional. Ademais, detectou-se que estão ocorrendo no Brasil nove Dinters e três Minters em Administração.

PALAVRAS-CHAVES: Alianças Estratégicas; Mestrados e Doutorados Interinstitucionais; Administração.

\section{STRATEGIC ALLIANCE BETWEEN INSTITUTIONS OF HIGHER EDUCATION: CREATING MASTERS AND DOCTORATES INTERINSTITUTIONAL}

\section{ABSTRACT}

he Higher Education Institutions (HEls) need to be alert to rapid economic, political, social and cultural changes in the globalized world and also flexible to the possibility to innovate their processes and services, favoring the chances of competitive advantage. To accompany these changes, companies seeking to invest in training and capacity building. Despite the marked expansion of undergraduate and postgraduate courses held in Brazil, we note that this improvement is still not enough and neither meets the needs of most Brazilian regions. In this scenario, there were the Masters and Doctorates Inter, seeking to empower professionals and create or expand research centers in disadvantaged geographic regions. Thus, we seek to ascertain how the alliances occur between IES; know the main benefits provided by these alliances for the institutions involved; identify the masters and doctorates inter occurring in Brazil in the Administration area. To do so, we carried out a survey, exploratory .The results show that the establishment of interagency partnerships is useful for HEls in medida em favoring sharing and creation of knowledge, thus adding value innovation in the educational market. Furthermore, it was detected that are occurring in Brazil Dinters nine and three Minters Administration.

KEYWORDS: Strategic Alliances; Masters and PhDs Inter; Administration.

\section{ISSN 2179-684X}

\section{SECTION: Articles}

TOPIC: Empreendedorismo e Inovação

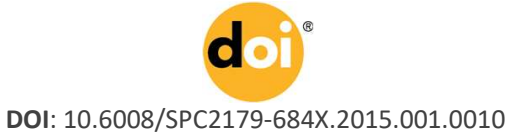

Francilene Araújo de Morais Universidade Presbiteriana Mackenzie, Brasil http://lattes.cnpq.br/1546276244212200 francilene-morais@ig.com.br

Moisés Ari Zilber

Universidade Presbiteriana Mackenzie, Brasil http://lattes.cnpq.br/0524413115146016 moises.zilber@mackenzie.br

Received: 27/08/2014

Approved: 14/10/2015

Reviewed anonymously in the process of blind peer.

\section{Referencing this:}

MORAIS, F. A.; ZILBER, M. A.. Aliança estratégica entre instituições de ensino superior: gerando mestrados e doutorados interinstitucionais. Revista Brasileira de Administração Científica, Aquidabã, v.6, n.1, p.164185, 2015. DOI: http://dx.doi.org/10.6008/SPC2179$684 X .2015 .001 .0010$ 


\section{INTRODUÇÃO}

As alianças entre empresas e/ou instituições, de segmentos iguais ou diferentes, de vários tamanhos, constituem uma das estratégias organizacionais que podem levá-las ao crescimento e expansão organizacional, na medida em que adquirem valor competitivo num mercado globalizado. Apesar de ser uma prática usada constantemente pelas empresas e indústrias dos ramos automobilísticos, biotecnológicos e de telecomunicações, trata-se de um assunto relativamente 'novo' no campo da educação (KLOTZLE, 2003). Entretanto, num contexto globalizado em que reina a gestão do conhecimento, as empresas, de modo geral, incluindo as do ramo de educação, precisam estar atentas às rápidas mudanças econômicas, políticas e mercadológicas ocorridas no mundo e também flexíveis para a possibilidade de ajustar-se e adaptar-se a estas mudanças, nem que, para isso, tenham que modificar sua forma de atuação para responder ao mercado.

Para Kraemer (2004), a necessidade de acompanhar as mencionadas mudanças de maneira rápida faz com que as empresas procurem investir em treinamentos e capacitações de seus profissionais. O mercado de trabalho, por sua vez, cada vez mais, exige profissionais qualificados para o exercício de suas funções, criando novas demandas para o setor de gestão de pessoas e também para o sistema educacional. Logo, segundo Ribeiro (2006), capacitar, treinar, informar, formar e desenvolver talentos são práticas ou alvos que são constantemente buscados e exercidos pelos profissionais que atuam na área de gestão de pessoas.

Com isto, numa visão contemporânea sobre gestão de pessoas, pode-se analisar que, para a gestão, não basta atrair e reter os melhores candidatos, mediante processos eficientes e eficazes de recrutamento e seleção. Em vez disso, as empresas também precisam criar condições para que os colaboradores permaneçam motivados, competentes e produtivos. Para tanto, as empresas podem investir em treinamentos técnicos, cursos de aperfeiçoamento, de graduação e de pós-graduação (DESSLER, 2005). De acordo com Ribeiro (2006), não se pode esquecer que o capital intelectual precisa ser continuamente 'cuidado' e que só desta forma as empresas podem permanecer competitivas no mercado. Num período de globalização, competição e de forte impacto da tecnologia, o desafio organizacional torna-se maior, no que se refere à sobrevivência, manutenção e expansão das organizações. Logo, a vantagem competitiva das empresas está na maneira de utilizar o conhecimento das pessoas para criar e inovar serviços e produtos. Para isso, as capacitações e o desenvolvimento cognitivo dos profissionais devem ocorrer de forma a otimizar as empresas.

Apesar da acentuada expansão de cursos de graduação e de pós-graduação ocorrida no Brasil, nota-se que este avanço ainda não é suficiente e nem atende às necessidades da maioria das regiões brasileiras em função de vários aspectos de cunho econômico, político, social e cultural. Nesse cenário, surgem no Brasil os Minters (Mestrados) e os Dinters (Doutorados) interinstitucionais. Trata-se de cursos de pós-graduação, oriundos de alianças estratégicas 
estabelecidas entre IES, que, entre outros aspectos, buscam capacitar profissionais e criar e/ou expandirem centros de pesquisas em regiões geográficas menos favorecidas, mediante a participação e experiência de instituições consolidadas, contribuindo, assim, para o desenvolvimento socioeconômico da região (CAPES, 2012).

Sendo assim, o objetivo principal deste artigo é verificar como ocorrem as alianças estratégicas entre IES e também conhecer os principais benefícios advindos destas alianças para as instituições envolvidas. Em relação aos objetivos específicos, procura-se identificar os Mestrados e Doutorados interinstitucionais que estão ocorrendo no Brasil na área de Administração. Para tanto, realizou-se uma pesquisa, de caráter exploratório, mediante revisão da literatura pertinente e análise dos relatórios sobre Minter e Dinter disponíveis no portal da CAPES.

Considera-se este estudo relevante investigação científica, uma vez que possibilita aos gestores refletirem sobre a utilidade dessas alianças para as IES, em termos de aprimoramento do capital intelectual e criação de "novos" conhecimentos, a partir do compartilhamento de conhecimentos entre as instituições promotoras e receptoras. Além disso, essas alianças podem contribuir para o desenvolvimento e expansão das instituições receptoras, na medida em que elas agregam vantagem competitiva, bem como para o desenvolvimento da região, onde estão inseridas.

Dessa forma, o presente artigo está dividido em seis partes. A primeira parte apresenta uma breve introdução sobre alianças estratégicas entre IES, destacando os Mestrados e Doutorados Interinstitucionais. Na segunda parte, realiza-se uma revisão teórica sobre os seguintes aspectos: conceitos de alianças estratégicas, fazendo uma ampliação deles, uma vez que são essencialmente de cunho mercadológico, para o âmbito dos Mestrados e Doutorados interinstitucionais, oriundos do estabelecimento de alianças estratégicas entre IES; tipos de alianças e fatores que interferem; relação entre alianças estratégicas, inovação e vantagem competitiva; benefícios das alianças estratégicas, destacando-se o compartilhamento e a criação de conhecimento entre IES. A terceira parte, por sua vez, aborda o âmbito deste estudo, destacando as alianças estratégicas entre IES, mediante análise exploratória dos editais da CAPES sobre o Mestrado (Minter) e o Doutorado (Dinter) Interinstitucionais. Na quarta parte, apresenta-se a metodologia. Na quinta parte, apresentam-se os resultados obtidos através da análise exploratória dos editais da CAPES e também os resultados obtidos através de pesquisas sobre Alianças Estratégicas na Área da Educação, fazendo um estudo dos Editais da CAPES do último triênio para projetos de Mestrado e Doutorado Interinstitucionais Nacionais, abarcando, os Minters e Dinters na Área de Administração. Por fim, na sexta e última parte, destacam-se as conclusões e considerações finais do estudo.

\section{REVISÃO TEÓRICA}

Alianças Estratégicas são uniões ou parcerias institucionais/ organizacionais entre dois ou mais estabelecimentos, em que uma das partes oferece serviços para outra parte, com o objetivo 
principal de gerar novos negócios ou benefícios para ambas às partes. Surgem como uma alternativa favorável às empresas, no que diz respeito à incorporação de habilidades necessárias que possam levá-las a adquirirem vantagem competitiva e também a consolidar sua posição no mercado (BARBOSA \& ZILBER, 2007). Vão desde simples contratos a joint ventures e consistem em acordos que envolvem vários aspectos das atividades fins das empresas envolvidas na parceria. Têm como finalidade principal aumentar a eficácia das estratégias competitivas das organizações participantes, possibilitando a troca mútua e benéfica de tecnologia e qualificações (TECHEMAYER \& PEDROSO, 2002).

Para Dussauge e Garrette (1999), a aliança é definida como estratégica quando envolve a junção e combinação das capacidades dos parceiros, compartilhando competências, a fim de expandir e diversificar os recursos da empresa. Além disso, esta estratégia passa a ser vista como uma fonte potencial, que proporciona aos parceiros envolvidos na transação: flexibilidade, redução nos custos, manutenção das competências essenciais, redução da necessidade da verticalização e economias diversas. Como o conceito de aliança estratégica não é unânime na academia, no que se refere a ser universalmente aceito, Klotzle (2003) revisou 17 estudos de autores diferentes, de renome nacional e internacional, que tratam deste assunto e chegou à conclusão de que alianças estratégicas podem assumir as seguintes formas: contratos unilaterais (licenças, acordos de distribuição); participação acionária (minoritária ou majoritária); joint venture internacional; fusões e aquisições; e contratos bilaterais.

Complementando as idéias de Klotzle (2003), Depamphilis (2003) destaca cinco tipos de alianças estratégicas: joint venture; com fins pré-estabelecidos; investimentos minoritários; franquia; e acordos de licença. A seguir, passamos a apresentar cada um deles. A joint venture consiste num relacionamento de cooperação, a fim de atingir um objetivo comum. As alianças com fins pré-estabelecidos vendem seus produtos para outros consumidores e/ou buscam inovar na criação ou na incrementação de produtos ou processos tecnológicos. A de investimentos minoritários é um tipo de aliança estratégica que requer pequeno comprometimento de tempo e gestão. Pode ser altamente líquida, se o investimento é uma empresa de capital aberto. Na franquia, o privilégio integral é dado a um revendedor de um produto industrial ou de serviço para vender os produtos franqueados com ou sem exclusividade. Já os acordos de licença requerem um capital inicial e representam um caminho conveniente para uma empresa disponibilizar sua mercadoria ou produtos para novos mercados.

Observando todos esses tipos de alianças estratégicas, pode-se dizer que as alianças interinstitucionais trazem para si uma ação cooperativista, em que as instituições preestabelecem, nas alianças fins, objetivos a serem alcançados e inovação, através de intercâmbios institucionais, utilizando o aperfeiçoamento de seus profissionais na área educacional. Assim como existem vários conceitos sobre alianças, segundo Yoshino e Rangan (1996), existem várias visões sobre o que seja e como ocorre a aliança estratégica, assim como os caminhos que cada organização irá seguir com o término da aliança. Ou seja: as empresas ficam independentes após a formação 
da aliança, a fim de atingir as metas conjuntamente estabelecidas; as empresas que participaram da aliança compartilham tanto dos benefícios gerados pela aliança, quanto controlam o desempenho das tarefas previamente definidas; e as empresas parceiras contribuem continuamente em uma ou mais áreas estratégicas cruciais.

O interesse pelas alianças estratégicas é marcado pela busca de crescimento organizacional, que ultrapassa as fronteiras da nacionalidade, das associações entre empresas, dos seus fornecedores e distribuidores. Trata-se de uma combinação de elementos competitivos e cooperativos num contexto de controle compartilhado (YOSHINO \& RANGAN,1996). Uma vez firmada a parceria, as empresas envolvidas passam a ter compromissos, que extrapolam os interesses individuais de cada organização. Tais compromissos envolvem os seguintes aspectos: participação e compartilhamento de capacidades entre os envolvidos; aumento no valor para ambas as empresas, o que pode gerar pressão nos concorrentes; obtenção de acesso a novas tecnologias e processos de produção, assim como aquisição de novos produtos e serviços; e qualificação de mão de obra, de acordo com as metas predefinidas pelas alianças (TECHEMAYER \& PEDROSO, 2002).

Partindo-se para o conceito de alianças estratégicas dentro de instituições de ensino superior, depara-se com problemas, porque a base conceitual em relação às alianças estratégicas em áreas educacionais é um tanto quanto escassa e seus conceitos estão, na maioria das vezes, ligados ao âmbito empresarial. Contudo, pode-se afirmar que, muito embora se comente sobre os conceitos de alianças estratégicas nas áreas de empresas, pode-se fazer uma analogia destes conceitos para utilizar nas instituições de nível superior, que constituem o foco deste estudo. Assim, as instituições e organizações, através das alianças estratégicas, buscam crescimento organizacional que ultrapasse as fronteiras da nacionalidade, das associações entre empresas, dos seus fornecedores e distribuidores, tratando-se de uma combinação de elementos competitivos e cooperativos num contexto de controle compartilhado. O mesmo acontece com instituições de ensino superior que visam programas de pós-graduação estrictu sensu, que preveem, em seus editais, parcerias entre as empresas envolvidas, passando a ter compromissos que extrapolam os interesses individuais de cada organização (CAPES, 2012). Tais compromissos envolvem aspectos como a participação e o compartilhamento de capacidades entre as instituições promotora e receptora, de forma a aumentar o valor e a capacitação para ambas empresas, o que pode gerar pressão nos concorrentes, tendo em vista a necessidade de ampliação da capacitação de seus profissionais. Assim, quando se obtém qualificação de mão de obra, de acordo com as metas predefinidas pelas alianças, há uma otimização das instituições como um todo.

Dessa forma, as alianças estabelecidas entre IES que originaram Dinter e Minter recomendados pela CAPES podem ser também analisadas como estratégicas, porque envolvem a junção e a combinação das capacidades dos parceiros, compartilhando competências, a fim de 
expandir e diversificar os recursos da empresa, neste caso específico, em relação à capacitação de profissionais na área educacional de instituições de ensino superior.

Com isso, as alianças estratégicas têm como finalidade a interação entre IES no desenvolvimento de capacitação profissional nos programas de pós-graduações, visando potencialmente proporcionar parcerias nas transações e inúmeros benefícios, tais como: flexibilidade, no que se refere a oferecer aos participantes cronogramas de atividades e calendários (incluindo dias, horários e locais), compatíveis com as necessidades das instituições promotoras e receptoras; redução nos custos das instituições; manutenção das competências essenciais; redução da necessidade da verticalização e economias diversas, de forma a desenvolver o aparato mercadológico entre as partes envolvidas.

Ainda na criação de uma aliança de valor, conforme Doz et al. (1998), cada parceiro deve compreender o valor de agir como equipe, isto é, cada instituição deve contribuir a fim de aumentar a probabilidade de ganhos. Assim, as equipes parceiras devem apreciar todos os benefícios decorrentes desta aliança. A partir daí, criar e desenvolver uma aliança de valor compreende que esta aliança compartilha um conjunto comum de lógicas subjacentes, que trarão benefícios entre os gestores, a partir de suas alianças e de suas estratégias, por meio da cooptação, desenvolvimento de tecnologia e coespecialização.

Pode-se analisar que, a partir do momento que as alianças estratégicas são capazes de fazer uma cooptação entre as instituições, transformam concorrentes em um âmbito mercadológico real e potencial em parceiros, que mutuamente se ajudam e desenvolvem o potencial de seus profissionais em meio ao mundo globalizado. Tal mundo está cada vez mais exigente em relação ao desenvolvimento dos profissionais para atuar dentro do mercado, que é constantemente alterado pela gama de conhecimentos que surgem em todos os lugares do mundo, de forma relativamente rápida.

Dessa forma, há uma corrida tecnológica em que as instituições criam novos mercados com suportes avançados (DOZ et al., 1998). Nesta visão, as alianças estratégicas também possibilitam uma coespecialização num mundo globalizado que, a cada momento, necessita de empresas cada vez mais aptas, e que seus profissionais sejam especializados para determinadas habilidades. Isso faz com que, através da coespecialização ofertada pelas alianças estratégicas entre ambas empresas, a empresa numa posição mais elevada de mercado sirva tanto de veículo para alavancar novos mercados e preencher lacunas, quanto para repassar conhecimentos para outras instituições que mantenham alianças com ela.

A implementação de uma aliança estratégica não é algo dado e nem facilmente implementado, uma vez que se trabalha com empresas/instituições totalmente diferentes e que envolvem uma série de fatores econômicos, sociais e culturais. Dessa forma, um dos fatores que, de certa forma, interfere nas alianças estratégicas é o relacionamento entre as empresas e/ ou instituições envolvidas nestas alianças, constituído pelas equipes locais e globais que são envolvidas com ações de cunho político local. Quando há o firmamento de uma aliança 
estratégica entre instituições, espera-se que a equipe local contribua com o conhecimento, instalando habilidades necessárias para o mercado local. Consequentemente, segundo Doz et al. (1998), o equilíbrio entre as equipes é condicionado pela natureza dos produtos envolvidos, pelas características do mercado e pela experiência da empresa global e pelas ambições das equipes parceiras.

O que se deve ter em mente é que as grandes dificuldades existentes para implementação de uma aliança estratégica dentro das instituições promotoras e receptoras são de grande relevância e utilidade, tendo em vista que as alianças estratégicas entre empresas possibilitam um aumento da rentabilidade e geração de valor para acionistas, inovação e vantagem competitiva, compartilhamento e criação de conhecimentos, além da preservação do capital intelectual na gestão do conhecimento. Tais fatores não ficam apenas no âmbito interno das instituições, mas rompem os muros das empresas/instituições, influenciando não apenas todo o ambiente local, mas também nacional e internacional.

Destaca-se que, segundo Afuah (1998), as alianças estratégicas podem gerar inovações tanto nos produtos quanto nos serviços. Inovação, estratégia ou planejamento e contexto competitivo são aspectos indissociáveis, seja ela uma inovação técnica, que ocorre sobre aprimoramentos/incrementos de produtos e serviços ou coisas completamente novas - ampliando este conceito, é o caso do que acontece com as alianças estratégicas em Dinter e Minter, que buscam o aprimoramento de profissionais através dos serviços que levarão os mesmo a capacitação; seja ela uma inovação administrativa, que abrange a estrutura organizacional e o processo administrativo, que podem ou não afetar inovações técnicas.

Assim, as alianças estratégicas têm em vista modelos de inovação incremental, porque se referem a melhoramentos de produtos ou serviços que correspondem à criação de novos produtos, isto é, no caso das IES, a instituição promotora deve ofertar serviços de capacitação em Dinter ou Minter para instituição receptora que, por sua vez, construirá outro serviço para ser ofertado à instituição promotora ou outras que necessitem do novo produto.

Igualmente, segundo klotzle (2003), a ampliação da integração dos mercados em todo mundo vem se tornando uma realidade cada vez mais presente, gerando uma nova ordem mundial que, por sua vez, traz reflexos para as organizações, principalmente no setor econômico, que passa a requerer das instituições a implantação de estratégias diferenciadas, a fim de não perder a competitividade nos grandes centros administrativos. Dessa maneira, a busca pela inovação e vantagem competitiva torna-se uma questão de sobrevivência para as empresas, independente do ramo em que elas atuam. Mas, como se desenvolve a inovação e a vantagem competitiva na ampliação de mercados, nas alianças estratégicas dentro de instituições educacionais dentro da nova ordem mundial? Pode-se dizer que estas 'novas' necessidades mundiais de inovação e vantagem competitiva atingem o aparato educacional do ensino superior, levando em consideração que há um acirramento da concorrência pelo fato de que muitas das exigências impostas pela globalização podem ser mais facilmente solucionadas - mesmo dentro 
de instituições educacionais - em conjunto com outras instituições. Com isso, essa vantagem competitiva surge com a aliança de uma instituição com outra para capacitar seus profissionais e, assim, competir com outras empresas, uma vez que as instituições nacionais e internacionais estão usando essas novas estratégias competitivas no estabelecimento de parcerias inter organizacionais ou alianças estratégicas como a que os editais da CAPES oferecem para alavancar seu potencial no mercado mundial.

Importante destacar que, se a empresa estiver atenta às mudanças das organizações do mercado global, a mesma vai buscar aproveitar as oportunidades para fazer e ser o diferencial, podendo seguir uma ou mais estratégias, como criar uma massa global crítica ou criar um novo mercado específico, tentando aprender rapidamente sobre mercados desconhecidos e tornar-se uma referência. Mas, para isso, é preciso acessar habilidades concentradas em outras e variadas economias, sociedades, culturas e localizações geográficas.

Segundo Faye et al. (2008), entende-se por compartilhamento de conhecimento o fato de a informação ser transmitida do emissor para o receptor, ficando o conhecimento tanto com o emissor quanto com o receptor. O compartilhamento de conhecimentos e a criação de novos conhecimentos, a partir das alianças estratégicas estabelecidas entre as IES, são entendidos como benefícios relevantes, na medida em que possibilitam a preservação e aprimoramento do seu principal recurso organizacional, que é o capital intelectual. Assim, através dos compartilhamentos e criação de 'novos' conhecimentos são gerados entre as alianças estratégicas das instituições o aperfeiçoamento de ambas. Assim, observa-se que o compartilhamento de conhecimento, a transferência de saberes, dá-se através das diferentes perspectivas, objetivos e interesses, não existindo uma superioridade de uma instituição sobre a outra.

Na literatura, Faye et al. (2008) abordam transferência de conhecimento sob a perspectiva de disseminação do conhecimento que constitui a base das abordagens linear, bidirecional e interativa. $\mathrm{Na}$ abordagem linear, os pesquisadores e especialistas geram conhecimentos e os repassam para os usuários, de maneira unidirecional, sem levar em consideração as preocupações e expectativas dos usuários. Já na abordagem dos modelos bidirecional e interativo, identificam-se as necessidades e preocupações dos futuros usuários, construindo, assim, um intercâmbio entre emissores e receptores. Observando as três abordagens, pode-se concluir que, nas alianças estratégicas entre as instituições de ensino superior, tendo em vista a fundamentação explanada nos editais da CAPES para projetos de Dinter e Minter, a abordagem que se pretende alcançar é a bidirecional, uma vez que há uma reciprocidade entre as instituições e o intercâmbio de saberes e conhecimento entre ambas.

Dependendo das abordagens e definições adotadas, existem diferentes processos ou modelos de transferência do conhecimento. Os principais modelos descritos por Faye et al. (2008) são: fluxo linear, colaborativo, interação, intercâmbio e partilha de conhecimento. No modelo de fluxo linear, que é eminentemente unidirecional, a transferência de conhecimento entre 
transmissores e receptores é representada por fluxos lineares/ unidirecionais. Trata-se de um aspecto dinâmico, no qual os emissores assumem um papel ativo e os receptores apresentam-se mais passivos. A influência do contexto e características individuais (nível, experiência etc.) sobre o processo ou sobre a finalidade da transferência está ausente. Analisa-se que este modelo de fluxo se torna um pouco distante das finalidades das alianças estratégicas pretendidas nos editais da CAPES, porque a busca dentro dos editais de alianças estratégicas em IES se dá pelo intercambio bilateral e recíproco entre as instituições.

No modelo colaborativo, evidenciam-se trocas regulares entre produtores e usuários do conhecimento. As trocas estabelecidas entre ambos são destinadas a integrar as preocupações dos usuários, podendo acontecer em várias de suas fases. Também são usadas para mostrar as relações que existem entre os dois centros de criação do conhecimento: pesquisa e ação. Estas relações são caracterizadas por um fluxo alternativo, contínuo e progressivo, que pode assumir a forma de uma espiral. Este fluxo se aproxima do pretendido entre as alianças estratégicas no que diz respeito às trocas de conhecimento integrarem as trocas de saberes entre as instituições.

No modelo de interação, a troca entre emissores e receptores é mais elaborada e ocorre de maneira circular. Este modelo está enquadrado diretamente com as alianças proposta pela CAPES, pois há relações de colaboração entre um conjunto de atores, e, por outro lado, uma reflexão sobre o contexto em que os usuários operaram e como a transferência de conhecimento ocorre. Nesse modelo, o conhecimento é o resultado de interações entre atores de diferentes sistemas, isto é, entre as instituições de ensino superior.

Em modelos de intercâmbio e partilha de conhecimento, o processo de interação entre os diversos grupos sociais, tais como pesquisadores tomadores de decisão e usuários, é central e resulta em redes de intercâmbio. O centro desses modelos é o produto final, ou seja, a utilização dos resultados, a avaliação do grau como os objetivos foram atingidos e a influência e impacto dos resultados por meio de sua aplicação e utilização. Esse modelo também traz uma similitude com as alianças estratégicas em ensino superior, pois pesquisadores produzem um conhecimento que pode ser melhorado por meio de feedback dos usuários, através de canais de intercâmbio.

A literatura trabalha as alianças estratégicas no sentido empresarial analisando fatores que facilitam a transferência de conhecimentos. Faye et al. (2008) informam que os mesmos irão variar de acordo com os objetivos pretendidos, a estratégia escolhida e o contexto organizacional. Considerando tal variação, é possível fazer uma abordagem em relação a instituições de ensino superior no que diz respeito a alguns fatores, destacando-se o fornecimento de conhecimento em tempo hábil de soluções sobre questões de interesse dos transmissores e usuários, a definição de uma estratégia clara de divulgação dos resultados desde o início, bem como a combinação de vários métodos para divulgação dos resultados, entre outros.

Com isso, nota-se que há uma série de impactos em relação ao conhecimento transferido na organização. Tais impactos podem provocar efeitos esperados, inesperados, positivos, negativos, dependendo do tipo de atividade e área organizacional, em que a transferência de 
conhecimento vai ocorrer. Entre os possíveis efeitos ou resultados da transferência do conhecimento, dentro das alianças estratégicas, aponta-se: valorização do conhecimento transferido para produtos e/ou serviços inovadores e rentáveis; subsídio de decisões organizacionais, com base no conhecimento transferido; contribuição do conhecimento transferido para o capital humano e para o capital técnico.

Devem-se levar em consideração que, apesar do teor objetivo e mecanizado do compartilhamento de conhecimento, podem ocorrer algumas dificuldades ou obstáculos na linguagem, emoções, crenças, valores etc. Podem-se analisar os problemas com a linguagem aparece em contextos em que os indivíduos, embora tenham conhecimentos, esbarram na dificuldade de compartilhá-los em função da falta de domínio do idioma. As emoções, crenças e valores, por sua vez, também interferem no compartilhamento de conhecimentos, tanto maximizando a relevância do conhecimento que precisa ser compartilhado quanto a minimizando. A vontade, o interesse, a necessidade de saber sobre um tipo particular de assunto são aspectos, que aliados à percepção, memória, atenção, esforço, persistência, concentração etc., interferem no compartilhamento de conhecimentos e, por conseguinte, na criação ou modificação de conhecimentos.

Morandim (2003) enfatiza que as emoções, os sentimentos e os modelos mentais dos indivíduos precisam ser compartilhados a fim de favorecer o desenvolvimento da confiança mútua. A confiança mútua é necessária à transferência de conhecimento, principalmente à do conhecimento tácito, assim como o estabelecimento de um ambiente onde os indivíduos interagem de forma cooperativa uns com os outros. Assim, nesse contexto de compartilhamento, os conhecimentos são criados e modificados.

Essas dificuldades também aparecem entre pessoas que compartilham o mesmo idioma e ocorrem devido à falta de habilidade de expressão oral. Dessa forma, a capacitação do profissional deve partir da premissa de que nem sempre um profissional vai trabalhar com outros profissionais do mesmo idioma, necessitando, assim, de uma qualificação que o leve a sanar determinados problemas ou dificuldades. Além disto, é comum, devido à interação de vários profissionais de diversos lugares do país e porque não dizer do mundo, deparar-se com valores, emoções e crenças diferentes das suas. Desse modo, é de extrema relevância o profissional saber interagir e entender aquele ser 'diferente' de si e aceitar, entender seus valores e posições diante de determinadas situações. Essa série de fatores tanto interfere no desenvolvimento das alianças estratégicas entre as instituições de ensino superior, quanto pode enriquecer a matéria, quando bem trabalhada, uma vez que instituições promotoras e receptoras tomam conhecimento de saberes diferentes, passando a entender melhor o motivo pelo qual dada ação é realizada de uma maneira e não de outra, em determinados lugares.

O conceito de conhecimento é amplo e pode ter diferentes significados, a depender do referencial filosófico e teórico. Podemos observar dois tipos de conhecimento, o tácito e o explícito. O primeiro refere-se ao conhecimento que é mais fácil de ser demonstrado do que 
codificado. Já o segundo corresponde ao conhecimento que é codificável e transmissível em linguagem formal.O compartilhamento de conhecimento envolve a transferência do conhecimento tácito e explícito entre os indivíduos dentro de uma organização (NONAKA \& TAKEUCHI, 1995; COLLINS,1993).

O conhecimento, para Nonaka e Takeuchi (1995), é criado e expandido através da interação social entre o conhecimento tácito e o conhecimento explícito, o que eles chamam de conversão do conhecimento, que pode ocorrer através de quatro modos, a partir da combinação entre o conhecimento tácito e o explícito: socialização (conversão do conhecimento tácito em conhecimento tácito); combinação (conversão do conhecimento explícito em conhecimento explícito); internalização (conversão do conhecimento explícito em conhecimento tácito); e externalização (conversão do conhecimento tácito em conhecimento explícito).

Para Nonaka et al. (2005), a criação do conhecimento requer uma atmosfera propícia, o que eles denominam de $\mathrm{Ba}$, termo japonês que se refere ao lugar ou espaço onde os indivíduos interagem. É no ambiente em que se organizarão as alianças estratégicas insterinstituicionais que ocorrerá a troca de ideias e o compartilhamento de conhecimentos, além da construção de uma linguagem comum, que sincronize os ritmos mentais e emocionais das pessoas, gerando conhecimentos. Nonaka e Bonno (1998) concebem quatro tipos de Ba. O primeiro tipo, originando $B a$, envolve o compartilhamento de sentimentos, emoções, experiências e modelos mentais, necessários na fase de socialização das alianças estratégicas entre as instituições promotoras e receptoras, em que esse compartilhamento ocorrerá face a face. O segundo tipo $B a$ associa-se à externalização do conhecimento e emerge a partir de cenários construídos. Assim, o conhecimento tácito torna-se explícito através do diálogo, reflexão e compartilhamento de modelos mentais. O terceiro tipo $B a$, o virtual, diz respeito ao uso da comunicação virtual na construção do $B a$, oferecendo um contexto para transmissão de conhecimento explícito para um maior número da população, por meio de equipamentos eletrônicos e outras mídias, como, por exemplo, grupos virtuais. O quarto e último tipo de $B a$ refere-se à prática do $B a$, que leva a internalização do conhecimento, que pode ocorrer através de monitoramento, treinamento, estágio etc.

No Ba ocorre o SECl, que significa a conversão de conhecimentos tácitos em explícitos. Os principais elementos do SECI são: socialização, externalização, combinação e internalização, de extrema relevância para a construção das alianças interinstitucionais. Analisa-se que o Ba em relação às alianças estratégicas dentro dos IES se torna ambiente propício à aprendizagem, que, por sua vez, depende de vários fatores, tais como: a tentativa e o erro, a observação e a escuta de histórias sobre como outras pessoas trataram problemas. Tipicamente ocorre mais no nível individual do que organizacional.

Por fim, observar, conversar, trocar experiências são maneiras pelas quais as pessoas descobrem o que sabem, compartilham conhecimentos e criam novos conhecimentos, que podem ter utilidade tanto para o indivíduo quanto para a organização. Importante destacar que, neste 
compartilhamento, podem ocorrer conflitos de ideias e, justamente, os diálogos estabelecidos podem levar as instituições emissoras e receptoras a redimensionarem seus conhecimentos e criarem novos conhecimentos.

Para que isso ocorra, é necessário o entendimento sobre a estrutura do conhecimento, sobre a qual Collins (1993) apresenta quatro elementos: simbólico, corporificado, mentalizado e introjetado pelas culturas. Simbólico refere-se ao conhecimento que pode ser transferido sem perdas, por meios de sinais, como o conhecimento que é transferido pela instituição entre computadores e demais mídias. Ou ainda podemos citar o conhecimento corporificado, que é o conhecimento que depende do corpo, tendo a ver com a parte física do cérebro e não com sua atuação cerebral, propriamente dita. Encontra-se aí o motivo pelo qual a CAPES faz a exigência nos editais de estrutura adequada para implementação dos Dinter e Minter. Por conseguinte, o conhecimento mentalizado realça o aspecto cerebral, no qual a geração de conhecimento ocorre através da seleção de objetos e ideias, que terá uma interatividade entre ambas as instituições. E, por ultimo, ainda tem-se o conhecimento aculturado ou conhecimento sociocultural, que depende do ambiente externo e da interpretação.

Dessa forma, o conhecimento pode ser transferido e decorre da ação humana, podendo apenas uma parte deste conhecimento ser transferida. A parte do conhecimento não suscetível de codificação ou mecanização fica na mente humana, aguardando o momento oportuno de ser utilizado. Em outras palavras, o indivíduo sabe que tem conhecimento, mas só se dá conta desta apropriação do saber quando surge uma necessidade e este conhecimento é externalizado. Com isto, podemos concluir que o conhecimento e habilidade são diferentes, e esta diferença ocorre em função das ações humanas de conhecimento tácito e conhecimento formal que são aflorados, de certa forma, através do impulsionamento dado entre as alianças estratégicas, tendo em vista o intercâmbio de informações, que é suscitado pelos programas de aperfeiçoamento profissional. Analisando-se mais profundamente, observa-se que o conhecimento tácito é o conhecimento que está localizado na sociedade, em contrapartida o conhecimento formal é o conhecimento que pode ser transferido para símbolos e codificado em máquinas e outros artefatos.

\section{Âmbito do Estudo}

O presente artigo tem como finalidade primordial analisar as alianças estratégicas entre instituições de ensino superior tendo como base o que os editais da CAPES exigem para a construção de projetos em alianças estratégicas interinstitucionais. Sendo assim, o foco do presente estudo está no âmbito da educação superior, possuindo intenções baseadas no art. 43, do capítulo IV, da Lei de Diretrizes e Bases da Educação Nacional- LDB (2013), em que são estabelecidas, em relação à educação superior, suas finalidades e no qual as universidades gozam da prerrogativa da autonomia, sendo-lhes asseguradas, dentre outras coisas, estabelecer planos, programas e projetos de pesquisa científica e de extensão, se assim entender as IES. 
Ainda de acordo com a referida lei, no art. 44,a educação superior abrange os cursos e programas sequenciais por campo de saber, de diferentes e diversos níveis de abrangência, principalmente programas de pós-graduação, compreendendo Mestrados e Doutorados, assim como também cursos de especialização, aperfeiçoamento e outros, abertos a candidatos diplomados em cursos de graduação e que atendam às exigências das instituições de ensino.

Conforme observado no artigo 44 da LDB, a carreira acadêmica profissional é construída pelo professor de maneira ascendente e marcada por vários estágios ou graus de complexidade, que vão desde os conhecimentos da graduação (licenciatura e bacharelado), passando pelo lato sensu (especialização), stricto sensu (Mestrado e Doutorado), podendo chegar até aos pósdoutorados. Apesar da passagem por estes graus evolutivos do conhecimento consistir em alvo ou meta a ser buscada pela maioria dos docentes, tal conquista ou realização nem sempre é fácil para a maioria dos professores brasileiros. A LDB em seu art. 44, inciso III, mostra a questão da oferta de Mestrados e Doutorados, assim como cursos de especialização como abrangência do ensino superior. Pode-se analisar que, entre os fatores que interferem nesta conquista, destaca-se o acesso, principalmente aos cursos do stricto sensu. A maioria destes centraliza-se em regiões geográficas mais favorecidas economicamente e que já têm consolidado centros de pesquisa, conforme informações disponíveis no portal da CAPES, em maio de 2014.

Com isto, surgem no Brasil, os Minters (Mestrados) e os Dinters (Doutorados) interinstitucionais que, entre outros aspectos, buscam capacitar profissionais e criar e/ou expandirem centros de pesquisas em regiões geográficas menos favorecidas, mediante a participação e experiência de instituições consolidadas, contribuindo, assim, para o desenvolvimento socioeconômico da região (CAPES, 2012). Entende-se o Minter/Dinter Nacional como propostas de Programas de Pós-Graduação stricto sensu entre duas instituições, em que uma instituição promotora oferecerá serviços de capacitação a uma instituição receptora, que receberá o programa para habilitação de seus alunos.

De acordo com os editais de abertura de projeto da CAPES, os projetos das instituições promotoras em Mestrado (Minter) ou Doutorado (Dinter) Interinstitucional devem ter notas reconhecidas pelo CNE/MEC igual ou superior a cinco. O que há de mais relevante nos projetos de Minter e Dinter é a interpelação que fazem entre as instituições promotoras e receptoras, uma vez que mantém cooperação interinstitucional, ação que viabiliza a formação de mestres e doutores em regiões que se encontram fora dos centros consolidados em ensino e pesquisa.

Para que esses projetos de Minter ou Dinter sejam submetidos à avaliação da CAPES, a instituição receptora precisa ter um espaço físico para beneficiar o projeto. Além disto, as atividades de ensino e pesquisa devem preservar o mesmo nível de qualidade do programa da instituição promotora. Com isto, a instituição promotora tem que ser responsável pelo curso a ser ofertado por seu programa de pós-graduação na instituição receptora(CAPES, 2012).

O objetivo primordial da CAPES com a oferta desses projetos em Minter e Dinter é a formação de mestres e doutores, associada à consolidação de grupos de pesquisa e ao 
fortalecimento e expansão da pós-graduação brasileira. Dessa forma, foi constatado pela CAPES, com a criação do programa Minter (Mestrados Interinstitucionais) e posterior extensão para Dinter (Doutorados Interinstitucionais), a partir de 1995, que ocorreram avanços significativos na redução das desigualdades inter e extra-regionais que existem na pós-graduação do país, tendo em vista que o programa faz com que haja um contato cooperativo na formação de recursos humanos qualificados, por meio dessas parcerias com programas de pós-graduação consolidados e reconhecidos.

Além disso, segundo informações disponibilizadas no portal da CAPES, os programas interinstitucionais possibilitam para ambas instituições: relacionamentos e troca de informações entre os representantes legais de diversas instituições educativas ibero-americanas; pactuar alianças e convênios; aprendizagem sobre práticas de internacionalização; informações sobre as últimas tendências na educação internacional.

Essa série de troca de saberes faz com que, de certa maneira, diminuam as barreiras existentes entre as instituições de todo o Brasil, pois a troca de informações faz com que os diversos pesquisadores passem a entrar em contato com novas e diversas vivências, para além das que se habituam e convivem em suas respectivas regiões, fato este que enriquece o ensino e o aprendizado em instituições de ensino superior. Ademais, verifica-se que os projetos não põem termo em si, pois, com os convênios, as instituições pactuam alianças que vão se perpetuando, indo além dos projetos.

\section{METODOLOGIA}

Trata-se de estudo exploratório realizado por meio de pesquisa com dados secundários obtidos dos relatórios da CAPES e Instituições de Ensino Superior nacionais com o sentido de buscar dados e informações sobre a existência de Minter e Dinter e suas características. De acordo com Gil (2008), a pesquisa exploratória tem como principal objetivo familiarizar-se com um assunto ainda pouco conhecido, pouco explorado.

Importante destacar que, apesar do tema alianças estratégicas entre empresas e/ou instituições ser uma prática usada constantemente pelas empresas e indústrias dos ramos automobilísticos, biotecnológicos e de telecomunicações, trata-se de um assunto relativamente 'novo' no campo da educação, justificando assim, o uso da metodologia exploratória.

A análise dos benefícios advindos das alianças estratégicas estabelecidas entre IES foi feita com base nos estudos de Nonaka et al. (2005) sobre o ambiente propício à construção ou criação do conhecimento, o que eles denominam de Ba e também na conversão de conhecimento tácito em explícito, o Seci. Além disso, levaram-se em consideração, os editais da CAPES (2011; 2012) para submissão de propostas por partes das IES, precisamente no que se refere aos objetivos que estas instituições pretendem alcançar e também a metodologia que usam para alcançarem tal fim. Importante destacar que os benefícios foram analisados em termos de 
expectativas do que se pretende alcançar, uma vez que as alianças analisadas estão ainda em fase de execução.

\section{RESULTADOS}

Os resultados obtidos, mediante análises da literatura pertinente e documentos disponíveis no portal da CAPES, são apresentados, levando-se em consideração os objetivos gerais e específicos preestabelecidos da presente pesquisa. Em relação à forma como ocorrem às alianças entre IES, que originam os Minters e os Dinters, notou-se que, apesar de ocorrerem em menor número, estas alianças acontecem de maneira semelhante às demais parcerias, que envolvem empresas e instituições de outros ramos, que não sejam os da educação, ou seja, levam em consideração as potencialidades das instituições promotoras e necessidades das instituições receptoras, com fins pré-estabelecidos. Notou-se ainda que o interesse por estas alianças é marcado pela busca do crescimento organizacional, que ultrapassa as fronteiras da nacionalidade e do teor meramente organizacional.

Assim, nas alianças entre IES, uma das partes, no caso a instituição promotora, oferece serviços para outra parte, à instituição receptora, com o objetivo primordial de gerar novos negócios ou benefícios para ambas as partes (BABOSA \& ZILBER, 2007).Como podem ser observadas, essas ações entre instituições são vistas como estratégicas, pois envolvem a junção e combinação das capacidades das instituições promotoras e receptoras, compartilhando competências, a fim de expandir e diversificar os recursos tanto das instituições promotoras quanto das instituições receptoras, tendo em vista que há uma troca de informações e de saberes de forma igualitária. Com isto, ao criar essas alianças, as instituições podem ser colocadas numa posição mais elevada de mercado, servindo de veículo para alavancar novos mercados e preencher lacunas.

Verificou-se, mediante os editais de abertura de projeto da CAPES, que, para as instituições promotoras oferecerem Mestrado (Minter) ou Doutorado (Dinter) Interinstitucional, além de ter notas reconhecidas pelo CNE/MEC igual ou superior a cinco, precisam manter cooperação interinstitucional, viabilizar a formação de mestres e doutores em regiões que se encontram fora dos centros consolidados em ensino e pesquisa. Em contrapartida, as instituições receptoras precisam disponibilizar um espaço físico para beneficiar o projeto. Além disso, as atividades de ensino e pesquisa devem preservar o mesmo nível de qualidade do programa da instituição promotora. Com isto, a instituição promotora tem que ser responsável pelo curso a ser ofertado por seu programa de pós-graduação na instituição receptora(CAPES, 2012).

Sendo assim, notou-se que ambas as instituições, promotora e receptora, procuram criar um BA, ou seja, uma atmosfera propícia à criação do conhecimento, favorecendo, assim, a troca de ideias, e o compartilhamento de conhecimentos, além da construção de uma linguagem comum, que sincronize os ritmos mentais e emocionais das pessoas, gerando conhecimentos, 
convertendo conhecimentos tácitos em explícitos, ou seja, o SECI (NONAKA et al., 2005; CAPES, 2011; CAPES, 2012).

Além disso, os Minters e os Dinters, a partir dos calendários e cronogramas de atividades elaborados pelas instituições promotora e receptora, possibilitam às pessoas envolvidas, seja na posição de condutores do processo (dirigentes das instituições promotoras e receptoras) ou na posição de usufruidores (alunos e professores), a oportunidade de observarem, conversarem e trocarem experiências, maneiras pelas quais as pessoas descobrem o que sabem, compartilham conhecimentos e criam novos conhecimentos, que podem ter utilidade tanto para o indivíduo quanto para a organização (NONAKA \& TAKEUCHI, 1995).

Concernente ao papel do capital intelectual na gestão do conhecimento, mediante os estudos que tratam de alianças estratégicas no âmbito educacional, averiguou-se acentuada necessidade de cuidar e preservar o capital intelectual, como recurso organizacional que poderá trazer inovação e vantagem competitiva para as instituições envolvidas. Desta forma, Ferraz et al. (2007) analisam que, no mundo globalizado em que se vive o fator diferencial das empresas, de modo geral, consiste em investir no desenvolvimento do capital humano. É de se observar que, segundo o autor, o capital humano, no mundo globalizado de constantes modificações, tornou-se mais importante do que o chamado capital tradicional, sendo a capacitação humana considerada atualmente como fonte de vantagem competitiva entre organizações.

Com isso, observa-se que, na era da gestão do conhecimento, investir no capital intelectual passa a ser um diferencial competitivo. No caso específico das instituições de ensino superior, que possuem como principal recurso o capital intelectual, trata-se, então, de algo essencial. Capacitar e desenvolver talentos, assim como originar e expandir centros de pesquisa passam a ser metas buscadas intensamente pelas instituições. Neste contexto, nascem os Dinters e Minters como uma alternativa para qualificar profissionais de regiões menos favorecidas, através de programas de pós-graduação já consolidados no país (CAPES, 2012).

No que diz respeito aos Mestrados e Doutorados interinstitucionais em Administração, que estão ocorrendo no Brasil, no último triênio, detectou-se que estão ocorrendo nove Dinters e três Minters, em diferentes regiões brasileiras: nordeste, sul, sudeste, norte. Ao analisar os editais de abertura para submissão de propostas de Mestrados e Doutorados interinstitucionais em Administração, recomendado pela CAPES, no último triênio, notou-se que os editais guardam semelhanças entre si, no que se refere aos objetivos gerais e específicos ao longo dos anos. Ou seja, os editais de seleção pretendem formar pessoas qualificadas para o desenvolvimento socioeconômico da região e ainda contribuir para o surgimento de novas vocações de pesquisa, ao mesmo passo que procuram possibilitar a participação de bolsistas de iniciação científica e estabelecer parcerias que viabilizem a disseminação da competência nacional em ciência e tecnologia (CAPES, 2011; CAPES, 2012; CAPES-EDITAL № 23/2014; CAPES, 2011; CAPES, 2012). 
A Agência de Inovação da Universidade Tecnológica Federal do Paraná, em parceria com o Núcleo de Gestão de Tecnologia e Inovação, desenvolveu um projeto, em 2009, denominado Programa de Capacitação UTFinova, realizado no estado do Paraná e no estado do Mato Grosso do Sul, respectivamente nas regiões Sul e Centro Oeste do Brasil, a fim de promover ações e políticas públicas de incentivo à inovação, através da capacitação de empresas e empresários (PENTEADO et al., 2013).

O principal objetivo deste projeto foi capacitar micro e pequenos empresários em temas correlatos à Gestão da Inovação, para melhoria da competitividade das empresas. Para alcançar este objetivo, realizou-se uma pesquisa qualitativa do tipo estudo de caso, com base em dados primários. A capacitação foi ministrada em dois períodos, por intermédio dos 11 campi da Universidade Tecnológica Federal do Paraná, nas cidades de Cornélio Procópio, Londrina, Apucarana, Campo Mourão, Ponta Grossa, Curitiba, Toledo, Medianeira, Francisco Beltrão, Pato Branco e Dois Vizinhos. Dez temas foram abordados no curso presencial de oito horas, totalizando 80 horas de curso: Gestão da Inovação - conceitos e processo; Geração e Seleção de Ideias; Instrumentos de Políticas de CT\&l; Redes e Alianças Estratégicas; Elaboração e Gerenciamento de Projetos; Gestão Financeira e de Riscos em Inovações; Metrologia, Normalização e Conformidade; Gestão do Conhecimento na Micro e Pequena Empresas (MPE); Propriedade Intelectual; Inovação, Sustentabilidade e Responsabilidade Social.

Em relação aos principais resultados obtidos, Penteado et al. (2013) destacam que, em 2011, a primeira edição do Programa contemplou 175 empresas e 399 empresários que participaram do curso em todos os 10 módulos. Já, na segunda edição, em 2012, contemplou mais 130 empresas no Paraná, com 197 empresários e, ainda no Mato Grosso do Sul, foram 22 empresas e 39 empresários participantes do Programa UTFinova.

Pode-se questionar: como uma pesquisa desse gênero relaciona-se com as alianças estratégicas em relação à Minter e Dinter entre os IES? O fato aqui é que a iniciativa, muito embora esteja ligada a um âmbito empresarial, neste viés, tem importância porque justamente trouxe à tona, no âmbito da pesquisa, diversos atores sociais no processo de inovação, tais como as agências de inovação e os grupos de pesquisa universitários, a exemplo da Agência de Inovação e do NGT, na disseminação e promoção da capacitação aos servidores e empresários estabelecidos nas regiões do entorno dos onze Campi da UTFPR e dos dois Campi do IFMS. Dessa forma, a pesquisa evidenciou alianças entre empresa e institutos de pesquisa e ensino superior para a otimização do âmbito empresarial.

Com isso, outro resultado significativo foi a utilização da metodologia do UTFinova como referência para elaboração e aprovação de mais um projeto de capacitação, agora com abrangência nacional, visando promover e fortalecer a cultura de inovação, protegendo a propriedade intelectual e estimulando o desenvolvimento tecnológico, a competitividade e a sustentabilidade dos empreendimentos inovadores no país. Por meio de uma pesquisa descritiva, feita com oito empresas que possuem ações na Bovespa, Moura et al. (2008) detectaram que as 
alianças estratégicas representam uma possibilidade concreta de reposicionamento competitivo, proporcionando, às organizações participantes, a conquista de vantagens competitivas por meio de investimentos em pesquisa e desenvolvimento. Os autores mencionados perceberam, também, que o desenvolvimento tecnológico é um fator decisivo na competitividade empresarial.

Investir em Pesquisa e Desenvolvimento (P\&D) favorece vantagens na inovação às organizações, tanto no processo, abrangendo vários métodos organizacionais, quanto no desenvolvimento de um novo produto ou adaptação ou extensão deste. As alianças que mais investem em P\&D são as horizontais, em comparação com as verticais. Nas alianças horizontais, as organizações participantes são complementares e buscam aumentar a sua competitividade no contexto globalizado. Já, nas alianças verticais, os compradores ou fornecedores podem resolver problemas de incerteza, decorrentes da P\&D, estimulando, assim, a inovação. Tendo como base todo este arcabouço, observa-se importante destacar que um tipo de aliança não exclui a outra, pois elas podem também coexistirem de maneira simultânea. As alianças tornam-se, assim, fator otimizador de empresas até mesmo com instituições de ensino superior, para capacitar os seus próprios profissionais para lidar melhor com o mundo globalizado, independentemente se esse profissional for ou não professor, conforme observam Moura et al. (2008).

Dessa maneira, pode-se afirmar que as alianças estratégicas entre universidade e empresa objetivam desenvolver novas tecnologias e a inovação, gerando vantagem competitiva às corporações nacionais em estágio de crescimento. Verificam-se, nos editais disponíveis no portal de transparência da CAPES do último triênio, a chamada pública de novas propostas de Mestrado e Doutorado interinstitucionais, Minter/ Dinter (nacional e internacional).Analisando os editais da CAPES, detectou-se a ausência do edital de 2013, mediante essa relevante lacuna, passou-se a analisar os editais referentes aos anos de 2011, 2012 e 2014, nos quais notam-se várias semelhanças, conforme descritas a seguir (CAPES, 2011; CAPES, 2012; CAPES, 2014). Observa-se que, nos objetivos gerais desses programas, contidos nos editais supracitados, não houve modificações ou alterações de maior significado ou que alterassem o objetivo primordial da implementação dos Dinters e Minters, ou seja, instruir propostas de Minter/Dinter, nacional e internacional, a fim de formar pessoas qualificadas para o desenvolvimento socioeconômico.

Com relação à analise dos objetivos específicos, verifica-se também que não houve alteração em seus textos, permanecendo, assim, os mesmos objetivos em todos os editais já citados, quais sejam: formar mestres e doutores fora dos centros consolidados de ensino e pesquisa, com um nível de qualidade similar; contribuir em temas de pesquisas sobre necessidades da região e que estendam o comprometimento da instituição para com a região; contribuir para o surgimento de novas vocações de pesquisa; possibilitar a participação de bolsistas de iniciação científica; estabelecer parcerias que viabilizem a disseminação da competência nacional em ciência e tecnologia. (CAPES, 2014)

E, por fim, em relação aos demais itens dos editais dos já citados anos da CAPE: Instituições Participantes da Proposta Minter/Dinter; Requisitos das Propostas a serem 
apresentadas; Apresentação das Propostas; Avaliação das Propostas, também não apresentaram mudanças significativas que alterassem a finalidade da CAPES mediante a implementação das alianças estratégicas, dentro do aparato interinstitucional de ensino superior.

Fazendo um recorte mais profícuo no presente artigo sobre alianças estratégicas, foi de relevância fazer uma análise dos projetos de Dinter e Minter dentro da proposta da CAPES. Dessa forma, buscou-se identificar os Dinters e Minters que estão ocorrendo no Brasil na área de Administração no último triênio. A CAPES lançou edital nos referidos anos para que as instituições de ensino superior submetessem seus projetos. Logo após, houve uma análise dos projetos inscritos na CAPES em Minter ou Dinter e posteriormente foram lançados os projetos aprovados tanto das IES promotoras quanto das receptoras.

Ao analisar as alianças estratégicas em Minter ou Dinter, foram detectados nos editais da CAPES: três Dinter, em resposta ao edital $n^{\circ}$ 013/2011; seis Dinter e três Minter em resposta ao edital nº 013/2012. Em 2013 não se detectou nenhum destes cursos, tendo em vista a ausência de edital do referente ano. Em10 de julho de 2014 observou-se que o edital ainda estava em aberto, o que indica que a seleção para os novos Minters e Dinters em Administração está ainda em fase de andamento. Observam-se, nos Quadros 1, 2, 3, Projetos de Doutorado Interinstitucional - Dinter 2011 e 2012 - respectivamente, que tiveram o financiamento aprovado pela CAPES. Nos referidos quadros, são apresentadas informações mais detalhadas sobre a oferta de projeto pela CAPES de alianças em Minter e Dinter, nas áreas de Administração(CAPES, 2011; CAPES, 2012).

Quadro 1: Projetos de Doutorados Interinstitucional - Dinter 2011 - que tiveram o financiamento aprovados pela CAPES.

\begin{tabular}{|l|l|l|}
\hline Área & IES Promotora & IES Receptora \\
\hline Administração & PUC & FUVERSA \\
\hline Administração de Empresas & PUC-RIO & IF Sudeste MG \\
\hline Administração & UNB & UFG \\
\hline
\end{tabular}

Fonte: Portal da CAPES.

Quadro 2: Projetos de Doutorados Interinstitucional - Dinter 2012 - que tiveram o financiamento aprovado pela CAPES.

\begin{tabular}{|l|l|l|}
\hline Área & IES Promotora & IES Receptora \\
\hline Administração & FUNDAÇÃO GETÚLIO VARGAS/SP/FGVISP & UNIVERSIDADE ESTADUAL DE MARINGÁ \\
\hline Administração & $\begin{array}{l}\text { UNIVERSIDADE FEDERAL DO RIO GRANDE DO } \\
\text { SUL/UFRGS }\end{array}$ & $\begin{array}{l}\text { UNIVERSIDADE COMUNITÁRIA DA REGIÃO DO } \\
\text { CHAPECÓ }\end{array}$ \\
\hline Administração & $\begin{array}{l}\text { UNIVERSIDADE DO VALE DO RIO DOS } \\
\text { SINOS/UNISINOS }\end{array}$ & UNIVERSIDADE DO ESTADO DE MATO GROSSO \\
\hline Administração & UNIVERSIDADE PRESBITERIANA MACKENZIE/UPM & FACULDADE DE CIÊNCIAS SOCIAIS APLICADAS \\
\hline Administração & $\begin{array}{l}\text { FUNDAÇÃO GETÚLIO VARGAS/RJ/ } \\
\text { FGV/RJ }\end{array}$ & UNIVERSIDADE FEDERAL DO ESPIIRITO SANTO \\
\hline Administração & UNIVERSIDADE FEDERAL DA BAHIA/UFBA & UNIVERSIDADE FEDERAL DO CEARÁ \\
\hline
\end{tabular}

Fonte: Portal da CAPES.

Quadro 3: Projetos de Mestrado Interinstitucional - Minter 2013 - que tiveram o financiamento aprovado pela CAPES.

\begin{tabular}{|l|l|l|}
\hline Área & IES Promotora & IES Receptora \\
\hline Administração & $\begin{array}{l}\text { PONTIFÍCIA UNIVERSIDADE CATÓLICA DO RIO } \\
\text { GRANDE DO SUL/PUC-RS }\end{array}$ & FACULDADE ASSIS GURGACZ \\
\hline $\begin{array}{l}\text { Administração de } \\
\text { Empresas }\end{array}$ & UNIVERSIDADE VALE DO ITAJAÍ/UNIVALI & $\begin{array}{l}\text { INSTITUTO FEDERAL DE EDUCAÇÃO CIÊNCIA E } \\
\text { TECN. DO MARANHÃO }\end{array}$ \\
\hline Administração & $\begin{array}{l}\text { PONTIFÍCIA UNIVERSIDADE CATÓLICA DO } \\
\text { PARANÁ/PUC-RS }\end{array}$ & $\begin{array}{l}\text { FACULDADE DE CIÊNCIAS SOCIAIS APLICADAS } \\
\text { DE CASCAVEL }\end{array}$ \\
\hline
\end{tabular}

Fonte: Portal da CAPES. 


\section{CONCLUSÕES}

A pesquisa aqui exposta teve como objetivo principal identificar como ocorrem as alianças estratégicas entre IES, que originaram os Minters e os Dinters nos anos de 2011, 2012 e 2013, bem como os principais benefícios advindos destas parcerias para as instituições envolvidas. Para tanto, foi necessário realizar uma revisão da literatura pertinente ao teor conceitual assim como a analise de documentos disponibilizados no portal da CAPES, tais como editais para submissão de propostas no último triênio e resultados dos Minters e Dinters aprovados pela mesma.

A revisão da literatura possibilitou averiguar que há escassez de estudos na área, sobretudo no segmento da educação. Uma explicação para tal ausência de trabalhos consiste na dificuldade de se obter dados sobre este tipo de aliança, uma vez que muitas informações sobre parcerias estratégicas, com exceção de fusões e aquisições, não são divulgadas constantemente pelos meios de informações especializadas. Com os novos estudos, sugere-se averiguar empiricamente os resultados ou benefícios advindos da conclusão dos mestrados e doutorados em andamento, em termos de crescimento e desenvolvimento regional.

A Educação no Brasil tem se mostrado numa expansão acentuada. Especificamente no ensino superior, esta expansão é expressiva, ao se analisar uma transformação no perfil do profissional brasileiro. O mercado tem exigido dos profissionais de ensino superior habilidades múltiplas e atualização constante do seu aparato cognitivo. Com isto, houve também uma acentuada expansão no ensino de pós-graduação no país, em que há uma procura cada vez maior desses profissionais para fazer cursos de mestrado e subsequentemente doutorado, o que faz com que os mesmos adquiriam maior visibilidade profissional, melhores salários, entre outros benefícios.

Esta pesquisa mostra que a formação de alianças e redes estratégicas proporciona uma excelente oportunidade para as empresas e instituições de ensino, tanto em relação à IES promotora, que cresce através da excelência de seu ensino, quanto para a IES receptora, em que a aliança permite a atuação local com uma instituição reconhecida nacionalmente pela sua qualidade em ensino. Mas, para a implementação de uma aliança estratégica interinstitucional, deve haver alguns cuidados na escolha dos parceiros e na metodologia utilizada para operar a aliança, que depende tanto do oferecimento de uma estrutura de qualidade quanto na oferta de um ensino de qualidade, que possibilite a integração eficaz da aliança formada.

Apesar de serem algo relativamente 'novo' na área da educação, as alianças estratégicas constituem uma alternativa relevante para o crescimento e desenvolvimento organizacional das instituições. Além disso, contribuem para o aprimoramento do capital intelectual e criação de centros de pesquisa. Dessa forma, o estudo aqui exposto é de grande relevância, tendo em vista que o mesmo abre portas para a pesquisa sobre alianças estratégicas interinstitucionais em Dinter e Minter. Sendo assim, espera-se que esta pesquisa estimule outras explorações mais profundas 
sobre o tema, que ampliem o conhecimento em relação à educação das alianças estratégicas dentro de ensino superior, que ocorre em todo o território nacional.

\section{REFERÊNCIAS}

AFUAH, A.. Innovation Management- Strategies, Implementation, and Profits. New York: Oxford University Press, 1998.

BARBOSA, C. A. P.; ZILBER, M.. A aliança estratégica como fator de vantagens competitivas em empresas de TI- Um estudo exploratório. Enanpad, p.1-16, 2007.

CAPES. Edital N 013/2011 Chamada Pública de Novas Propostas de Mestrado e Doutorado Interinstitucionais, Minter/Dinter Nacional e Internacional. Brasilia: CAPES, 2011.

CAPES. Projetos de Doutorado Interinstitucional- Dinter 2011- que tiveram o financiamento aprovado pela CAPES. Brasilia: CAPES, 2011.

CAPES. Minter/ Dinter 2012. Brasilia: CAPES, 2012.

CAPES. Novas Propostas de Mestrado e Doutorado Interinstitucionais, Minter/Dinter Nacionais e Internacionais- Edital Nº13/2012. Brasilia: CAPES, 2012.

CAPES. Resultado Minter/Dinter 2012- Propostas Recomendadas. Brasilia: CAPES, 2012.

CAPES. EDITAL № 23/2014. Novos Projetos de Mestrado e Doutorado Interinstitucionais, MINTER/DINTER nacionais e internacionais. Brasilia: CAPES, 2014.

COLLINS, H..The Structure of Knowledge. Social Research, v.60, p.116, 1993.

DEPAMPHILIS, D. M.. Mergers, Acquisitions and other restructuring activities- An integrated approach to process, tools, cases and solutions. San Diego: Elsevier Science, 2003.

DESSLER, G.. Administração de Recursos Humanos. São Paulo: Prentice Hall, 2005.

DOZ, Y.; HAMEL, G.. Alliance Advantage: The artofcreatingvaluethroughpartnering. In Harvard Business School Press Boston, 1998.

DUSSAUGE, P.; GARRETE, B.. Cooperative strategy. England: John Wiley \& Sons, 1999.

FAYE, C.; LORTIE, M.; DESMARAIS, L.. Guide to Knowledge Transfer-Designed for Researchers in Occupational Health and Safety. Québec : Réseau de recherche en santé et en sécurité du travail du Québec, 2008.

FERRAZ, S.; DERISIO, D. P. L.; CRISPIM, S. F.. Capital Humano: Fonte de Vantagem Competitiva ?- A Visão de Duas Organizações do Setor Farmacêutico. In: ENCONTRO DE GESTÃO DE PESSOAS E RELAÇÕES DE TRABALHO. Anais. Natal: EnGPR, 2007.

GIL, A. C..Como elaborar projetos de pesquisa. 5 ed. São Paulo: Atlas, 2008.

KLOTZLE, M. C.. O impacto da formação de alianças estratégicas no valor de mercado e no desempenho econômico-financeiro das empresas. Caderno de Pesquisas em Administração, v.10, n.04, p.33-46, 2003.

KRAEMER, M. E. P.. Universidade Corporativa como Alavanca da Vantagem Competitiva. Revista Eletrônica de Ciência Administrativa, v.3, n.1, 2004.

BRASIL. lei $n^{\circ}$ 9.394, de 20 de dezembro de 1996. Dispoem sobre as diretrizes e bases da educação nacional. Brasilia, 20 Dez 1996. 
MORANDIM, D. R. A. L.. A Influência da Confiança na Transferência do Conhecimento. Dissertação (Mestrado em Administração de Empresas) - MAckenzie, São Paulo, 2003.

NONAKA, I.; TAKEUCHI, H.. How japanese companies creates the dynamics of innovation. Oxford University Press, p.284-285, 1995.

NONAKA, I.; TOYAMA, R.; KONNO, N.. SECl, ba and leadership: a unified model of dynamic knowledge creation. Knowledge Management, v.33, p.5-34, 2005.

PENTEADO, R. F. S.; CARVALHO, H. G.; STRAHUS, F. R.. Capacitação para empresários do Paraná e Mato Grosso do Sul em Empreendedorismo Inovador: Programa Utfinova. Curitiba: Universidade Tecnológica Federal o Paraná, 2013.

RIBEIRO, A. L.. Gestão de pessoas. São Paulo: Saraiva, 2006.

TECHEMAYER, C. A.;PEDROSO, E. A.. O processo de formação e gestão de alianças estratégicas: proposta de um modelo de análise. In: ENCONTRO NACIONAL DE ASSOCIAÇÃO DE PÓSGRADUAÇÃO E PESQUISA EM ADMINISTRAÇÃO. 24. Anais. São Paulo: EnANPAD, 2002.

YOSHINO, M. Y.; RANGAN, U. S.. Alianças estratégicas: Uma abordagem empresarial à globalização. Sao Paulo: Makron Books, 1996. 